\title{
Forum
}

\section{Whose body is it anyway: paternalism and Section 57 of the Mental Health Act 1983}

\author{
Femi OYebode, Consultant Psychiatrist, Queen Elizabeth Psychiatric Hospital, \\ Edgbaston, Birmingham B15 2QZ
}

Section 57 of the Mental Health Act 1983 relates to certain forms of medical treatments for mental disorder which require both consent and a second opinion. It applies to any surgical operation for destroying brain tissue or for destroying the functioning of brain tissue; it also applies to the surgical implantation of hormones for the suppression of male sexual drive. These treatments cannot be given unless the patient has consented and three independent people, including a medical practitioner, certify that the patient is capable of understanding the nature of the treatment proposed, has consented to it, and the appointed registered medical practitioner has certified that the treatment is appropriate. This paper examines whether Section 57 is indeed justifiable and whether the current procedure needs amendment.

\section{Paternalism}

The Code of Practice states that Section 57 reflects public and professional concern about particular forms of treatment and that such treatments need to be considered carefully in view of the possible longterm effects and the ethical issues that arise. The nature of the public and professional concern about psychosurgery or surgical hormonal implantation is not specified. Neither a distinctive quality of the long-term effects nor the ethical issues are described. The assumption appears to be that these are all self-evident. The implicit statement in the Code of Practice is that the provisions of Section 57 are designed to benefit patients and to protect their interests. The concern for the patient's welfare is so great that the possibility of overriding the patient's wish to undergo the procedure is deemed justifiable. This is a clear example of paternalism.

Paternalism can be understood as the overriding of a person's wishes or actions by another for beneficent reasons. Where the interference is with the independent wishes or actions of a competent person such that his or her free choice is limited, the burden of justification is that much heavier (Beauchamp \& Childress, 1983). It has also been argued that the only acceptable justification for interference in another person's liberty is where it can be shown that others are at risk from harm (Mill, 1859); this is the view that antipaternalists hold. The belief here is that the autonomous person can ascertain his or her best interests more competently than anyone else. This belief does not depend upon the likelihood that a person will be able to make better choices, given the same situation, than anyone else. The value attaches simply to a person's freedom to make certain choices such as consent to or refusal of medical treatment (Childress, 1982).

The main thrust of the procedure of Section 57 is to establish that the patient is competent to give consent and has indeed given consent. There is a danger here that this provision can be seen as evidence that psychiatric patients are unable to form a conception of good and bad, of benefits and harms, or are unable to act upon these conceptions in particular circumstances, such that there is a need to establish their competence to consent in particular circumstances. There is no empirical evidence that psychiatric patients who consent to any form of treatment, including treatments for physical conditions, are any less competent than anybody else to consent or less informed about what they have consented to. (This may not apply to patients who are mentally impaired.) Because patients sometimes refuse to give their consent for treatments and are then deemed incompetent and consequently detained, does not mean that when they give their consent in other settings, their capacity to do so should be in doubt.

\section{Justified paternalism?}

If Section $\mathbf{5 7}$ is a paternalistic provision, is it justifiably so? Paternalism may be justifiable where the harm prevented or the benefit provided outweighs the loss of independence or the sense of invasion suffered through the interference, and where the person's illness limits the ability to choose. Some authors argue that both conditions are jointly necessary in order to fulfil the requirements of justified 
paternalism. Where only the first condition is present this would amount to a case of strong paternalism, and the autonomy of the individual would then be seen as having been compromised.

The question is whether these requirements are met in the case of Section 57. The harms which Section 57 seeks to prevent include the performance of inappropriate psychosurgery on a non-consenting or incompetent patient. It is argued that since psychosurgery is irreversible and has long-term consequences such as alteration in behaviour and psychological status, strict rules should apply to its use. It is further argued that psychosurgery is undesirable because it is surgery on normal brain tissue to produce psychological effects and the brain has special status as the seat of our volitional and rational capacities, and our sense of self (Buchanan \& Brock, 1989). If this is true, then in the cases where the Section 57 acts to validate the decision and wishes of a competent and consenting patient, the limited interference in the patient's autonomy may be a small price to pay for the harms which are, theoretically, prevented. However, where competent and consenting patients, whose desire for surgery is contrary to the opinion of the appointed registered medical practitioner, are denied surgery, this would count as strong paternalism. In such cases the autonomy of a competent patient would have been violated.

It is important to emphasise that the argument that there is something different in kind about psychosurgery as opposed to other forms of brain surgery, or even of surgery in general, is not without difficulty. Most forms of surgery, for example limb amputations, have long-term effects. Temporal lobectomy for chronic and intractable epilepsy may have as one of its aims the improvement of behaviour, and thalamotomy for pain is another example of surgery upon normal brain tissue to control an effect (pain is regarded by some authors as an affect). These examples show that disquiet about psychosurgery is founded upon other facts such as the history of the misuse of prefrontal lobotomies earlier this century and upon the potential for abuse.

\section{Section 57 procedure}

The current procedure allows for the interviewing of the patient by the Section 57 panel, usually at the referring hospital at an early stage in the process, shortly before the date of the proposed operation. The main drawback of the current procedure is its timing. The visit of the panel can easily be perceived as an obstacle rather than as a mechanism aimed at protecting the interests of the patient. This perception is reinforced by the fact that all the other parties, i.e. the patient, his or her relatives, the referring doctor, and the specialist unit, have agreed in principle about the desirability of surgery. The panel's decision is therefore weighted towards agreeing with the decision of the other parties. It could be argued that the panel's freedom of action is limited in a covert way. The role of the appointed doctor in this situation cannot be properly described as providing an independent medical opinion about diagnosis and possible treatments. The role is restricted simply to whether or not psychosurgery is appropriate.

The timing of the panel's visit could be altered such that the patient's responsible medical officer (RMO) informs the Mental Health Act Commission much earlier in the process, namely before the referral to the specialist psychosurgical service. The aim would be for an independent and expert opinion to be sought on the appropriateness of psychosurgery in the given case, and for an assessment of the patient to give valid consent to such a treatment. In this way issues relating to alternative forms of treatment could be discussed without appearing to jeopardise a predetermined goal that had been consented to by the patient. If psychotherapy were deemed appropriate and the patient capable of consenting, a referral by the patient's RMO would proceed in the usual way to the specialist service, leaving the way open for a competent person to make an informed choice without interference by third parties.

There is a need to monitor the number of operations performed annually, and also the kinds of operations in use and any innovative techniques in the field. This means that centres which are involved in this area may have to be licensed with the Commission, with the statutory obligation that they provide particular information on an annual basis and also that they be visited or inspected annually by the Commission. Indeed, this arrangement may provide more safeguards for patients than is now available.

\section{Conclusion}

The provision of Section 57 is paternalistic in kind, but in my view this is justified. However, there is a need to amend the procedure of the provision, in order to limit the interference in the autonomy of patients and also to facilitate the role of the panel of appointed persons. This would require an alteration in the current legislation.

\section{References}

Beauchamp, T. L. \& Childress, J. F. (1983) Principles Biomedical Ethics, 2nd edition. Oxford University Press. Buchanan, A. E. \& Brock, D. W. (1989) Deciding For Others: the ethics of surrogate decision making. Cambridge University Press.

ChILDREss, J. F. (1982) Who Should Decide? Oxford Univeristy Press.

MıLL, J. S. (1859) On liberty. In Utilitarianism (ed. M. Warnock). London: Fontana Press. 